\title{
Research on anchor service life base on grey prediction model
}

\author{
Xinzheng Wang \\ Academy of Civil Engineering and Architecture, Nanyang Normal University, Nanyang 473061, China \\ wxz791023@126.com
}

\begin{abstract}
With the wide application of anchored structures in various engineering, their durability and service life have become an important issue in the development of anchoring technique. According to the corrosion experiment results on different working conditions (close and damp, permanently soaked in water, wet and dry alternately, weak acidity aqueous soaking), and on the basis of determining the loss rate threshold of anchor steel reinforcement bearing capacity, this paper first test the experiment data and then predict the service life of anchor steel on four different working conditions by adopting $G M(1,1)$ model. The results indicate that the grey prediction has high accuracy.
\end{abstract}

KEYWORDS. Anchor; Service life; Grey prediction; GM (1,1).

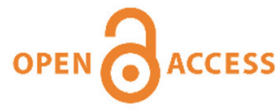

Citation: Wang, X.Z., Research on anchor service life base on grey prediction model, Frattura ed Integrità Strutturale, 45 (2018) 100-107.

Received: 29.03.2018

Accepted: 11.06 .2018

Published: 01.07.2018

Copyright: (C) 2018 This is an open access article under the terms of the CC-BY 4.0, which permits unrestricted use, distribution, and reproduction in any medium, provided the original author and source are credited.

\section{INTRODUCTION}

Ir he bolt and cable supporting is convenient and fast in construction, low in cost and adaptable to engineering [1-3]. It is widely used in rock and soil slope supporting engineering in water conservancy and hydropower, railway, highway, construction and other industries. In the course of using the anchor structure, how long their residual life is, and whether they will suddenly failure one day has become a common concern. Therefore, it is of great importance significance to study the durability and service life of the anchor. By combining the indoor experiment with theoretical analysis, this paper analyzes the experimental result indoors through the use of Grey Theory, and based on the experimental result of limit tension anchor rod on site, studies the durability and service life of anchored structures.

According to the corrosion experiment results on different work condition (close and damp, permanently soaked in water, wet and dry alternately, weak acidity aqueous soaking)) and on the base of determining the critical breakage of carrying capacity loss rate, this paper first examines the experiment data and then predict the service life of anchor rod on 4 different work conditions by adopting $\mathrm{GM}(1,1)$ model. At last, the predicting result is compared with the testing result of the anchor rod. The results indicate that the grey prediction has high accuracy.

\section{OVERVIEW OF GREY SYSTEM THEORY}

The concept of grey prediction

7 he Grey Theory studies few data and indetermination. It understands and knows the world by creating and opening out the "part" known information, and then it can correctly hold and depict the functional behavior and evolutive rules of the system. It can successfully solve many practical problems in production, life and scientific re- 
search. This theory has been broadly used in many engineering fields.

Grey prediction is based on the processing of raw data and the establishment of grey model, find and master the development law of the system, and make a scientific and quantitative prediction of the future state of the system [4-7]. Grey prediction model generally refers to $G M(1,1)$ model.

GM $(1,1)$ model

Make $x^{(0)}$ is the modeling sequence of $G M(1,1)$ : $X^{(0)}=\left(x^{(0)}(1), x^{(0)}(2), \wedge, x^{(0)}(n)\right)$, and make $x^{(1)}$ is the AGO sequence of $x^{(0)}: X^{(1)}=\left(x^{(1)}(1), x^{(1)}(2), \wedge, x^{(1)}(n)\right)$,

$$
x^{(1)}(1)=x^{(0)}(1), x^{(1)}(k)=\sum_{m=1}^{k} x^{(0)}(m)
$$

Make $z^{(1)}(k)$ is the mean sequence of $x^{(1)}(k)$

$$
\begin{aligned}
& z^{(1)}(k)=0.5 x^{(1)}(k)+0.5 x^{(1)}(k-1) \\
& Z^{(1)}(k)=\left(Z x^{(1)}(2), Z x^{(1)}(3), \wedge, Z x^{(1)}(n)\right)
\end{aligned}
$$

The definition type of $G M(1,1)$, that is, the grey differential equation model of $G M(1,1)$ is:

$$
x^{(0)}(k)+a q^{(1)}(k)=b, k=1,2, \ldots, n
$$

In the formula: $a$ and $b$ are constants, among them, $a$ is development coefficient, $b$ is grey influencing coefficients. The GM (1,1) definition equation can be transformed into matrix equations.

$$
\begin{aligned}
& Y_{N}=B P \\
& Y_{\mathrm{N}}=\left[x^{(0)}(2), x^{(0)}(3), \cdots, x^{(0)}(n)\right]^{\mathrm{T}} \\
& B=\left[\begin{array}{cc}
-z^{(1)}(2) & 1 \\
-z^{(1)}(3) & 1 \\
\vdots & \vdots \\
-z^{(1)}(n) & 1
\end{array}\right] \\
& P=\left[\begin{array}{l}
a \\
b
\end{array}\right] .
\end{aligned}
$$

Under the least square criterion, the solution of $Y_{N}=B P$ is:

$$
P=\left[\begin{array}{l}
a \\
b
\end{array}\right] \cdot=\left(B^{T} B\right)^{-1} B^{T} Y_{N}
$$

Substitute $B$ and $Y_{N}$ into the formula, it can calculate the value of $a$ and $b$. The detailed formula of $G M(1,1)$ grey prediction model is obtained. When $k=0,1,2, \ldots, n$, the original sequence fitting value is obtained, for $k=n+1$, a prediction value of the original sequence is obtained, and a multi-step prediction can be obtained at one time. 


\section{CORROSION TEST OF ANCHOR STEEL}

$\mathrm{C}$ orrosion is the most important factor affecting the service life of anchor steel. When the corrosion is slight, the tensile capacity of the steel bar is calculated according to the remaining cross-sectional area, without considering the strength reduction of the steel bar. When the steel bar is corroded to a certain extent, not only the sectional area of the steel bar is decreased, but also the strength and ductility of the steel bar have different rate reduce. When the steel corrosion is serious, the stress-strain curve of the steel bar has changed greatly. There is no obvious yield point on the curve, and the yield strength is very close to the tensile strength, it is very easy to cause the sudden brittle fracture of the structure [8-10].

\section{Steel bar corrosion mechanism}

The chemical composition and mechanical properties of the steel used in the test are shown in Tab. 1.

\begin{tabular}{|c|c|c|c|c|c|c|c|c|}
\hline \multicolumn{6}{|c|}{ Chemical composition } & \multirow{2}{*}{$\mathrm{R}_{\mathrm{el}} / \mathrm{MPa}$} & \multirow{2}{*}{$\mathrm{R}_{\mathrm{m}} / \mathrm{MPa}$} & \multirow{2}{*}{$\begin{array}{c}20^{\circ} \mathrm{C} \text { Impact en- } \\
\text { ergy } / A_{K} / J\end{array}$} \\
\hline $\mathrm{C}$ & $\mathrm{Si}$ & $\mathrm{Mn}$ & S & $\mathrm{P}$ & V & & & \\
\hline 0.26 & 0.56 & 1.57 & 0.011 & 0.024 & 0.107 & 705 & 875 & 35 \\
\hline
\end{tabular}

Table 1: The chemical composition and mechanical properties of the steel.

The corrosion of anchor steel is an electrochemical corrosion process, mainly through the following four processes.

(1) The process of anodic reaction. The iron atom in the anode region is transformed into cationic, and the electron is released. The equation of reaction is:

$$
\mathrm{Fe} \rightarrow \mathrm{Fe}^{2+}+2 e^{2-}
$$

(2) The process of electron transport. The electrons which released from anode region are transferred through steel to the cathode region.

(3) The process of cathode region. In the vicinity of the cathode region, the oxygen dissolved in the pore water absorbs electrons and occurs reduction reaction. The equation of reaction is:

$$
\mathrm{O}_{2}+2 \mathrm{H}_{2} \mathrm{O}+4 e^{-} \rightarrow 4 \mathrm{OH}^{-}
$$

The $\mathrm{OH}_{-}$produced at the cathode is sent to the anode through the liquid phase in the concrete pore, thus, a closed loop of corrosion current is formed [11-15].

(4) The formation process of corrosion products. The $\mathrm{Fe}^{2+}$ generated in the anode region diffused and migrated in the aqueous solution, the $\mathrm{OH}$ - generated in the cathode zone diffuses through the pores in the concrete to the anode region. Near the anode, $\mathrm{Fe}^{2+}$ and $\mathrm{OH}$ - form insoluble $\mathrm{Fe}(\mathrm{OH})_{2}$, and oxidize to $\mathrm{Fe}(\mathrm{OH})_{3}$ under oxygen enrichment.

$$
\begin{aligned}
& \mathrm{Fe}^{2+}+2 \mathrm{OH}^{-} \rightarrow \mathrm{Fe}(\mathrm{OH})_{2} \\
& 4 \mathrm{Fe}(\mathrm{OH})_{2}+\mathrm{O}_{2}+2 \mathrm{H}_{2} \mathrm{O} \rightarrow 4 \mathrm{Fe}(\mathrm{OH})_{3}
\end{aligned}
$$

After $\mathrm{Fe}(\mathrm{OH})_{3}$ dehydration, it becomes loose and porous red embroidered $\mathrm{Fe}_{2} \mathrm{O}_{3}$, that is:

$$
2 \mathrm{Fe}(\mathrm{OH})_{3} \rightarrow \mathrm{Fe}_{2} \mathrm{O}_{3}+3 \mathrm{H}_{2} \mathrm{O}
$$

Under the condition of less oxygen, $\mathrm{Fe}(\mathrm{OH})_{2}$ oxidation is not complete, and part of $\mathrm{Fe}(\mathrm{OH})_{2}$ forms $\mathrm{Fe}_{3} \mathrm{O}_{4}$, that is:

$$
6 \mathrm{Fe}(\mathrm{OH})_{2}+\mathrm{O}_{2} \rightarrow 2 \mathrm{Fe}_{3} \mathrm{O}_{4}+6 \mathrm{H}_{2} \mathrm{O}
$$

Therefore, the final corrosion product depends on the oxygen supply. 
Experimental design

The dimension of the specimen steel is $\Phi 8 \times 40 \mathrm{~mm}$. Clean the oil of the specimen bar and place it in a dry container. Specimens were placed in four environments: close and damp, permanently soaked in water, wet and dry alternately, weak acidity aqueous soaking. The close and damp means that the specimen is hung above the water surface in the sealed container. The permanently soaked in water means that the specimen is located below the water level in the sealed container. The wet and dry alternately means that the specimen is located below the water level for 7 days, and the other 7 days is located above the water level in the container, and so on alternately, the container is open. The weak acidity aqueous soaking means that the dilute sulfuric acid and tap water was used to prepare soaking solution, and the soaking solution is used to simulate the acid environment, immerse the specimen permanently below the surface of the acid solution in the sealed container. All of the above corrosion environments change soaking liquid once a month [16-20].

\section{Experimental result}

The experimental results are shown in Fig. 1.

(1) As can be seen from Fig. 1, in the four different corrosion environments, the weight loss rate of steel is the largest in the weak acid aqueous solution and the minimum in the close and damp environment.

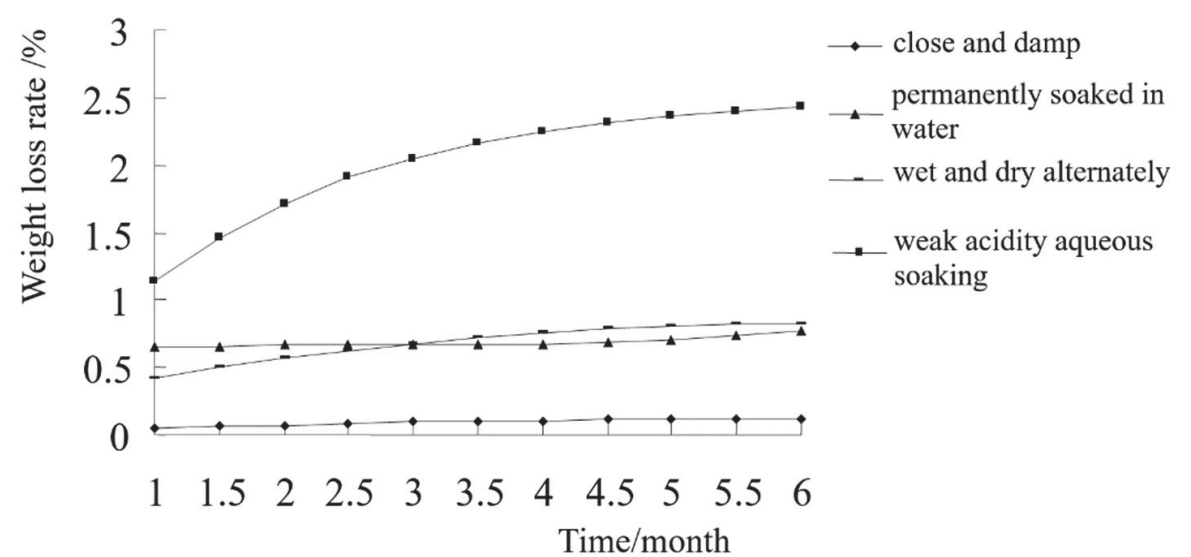

Figure 1: Distribution of anchor steel weight loss rate with time

(2) The rate of weight loss of steel in wet and dry alternately is almost the same as that in permanently soaked in water, but the growth rate of weight loss rate in the wet and dry alternately condition is greater than the permanently soaked in water condition.

(3) The weight loss rate of the anchor steel in close and damp condition is only about 1/5 of the anchor steel in the condition of permanently soaked in water condition and wet and dry alternately condition.

(4) In any experimental environment, the weight loss rate of anchor steel increases with time, but the increase rate decreases with time.

\section{THE ANALYSIS OF GREY PREDICTION}

\section{Determination of the bearing capacity loss threshold of steel bars}

T $\mathrm{n}$ practical engineering, the bearing capacity of steel bars direct influence on the structural safety, therefore, the bearing capacity loss rate of the steel bars is taken as the damage criterion. The bearing capacity loss rate of steel bars can be expressed as:

$$
\frac{\Delta P}{P}=\frac{f_{\mathrm{y} 0} S_{0}-f_{\mathrm{y}}^{\prime} S_{1}}{f_{\mathrm{y} 0} S_{0}} \times 100 \%
$$

In the formula, $\Delta P$ — the decrement of bearing capacity $(\mathrm{KN}) ; P$ - initial bearing capacity $(\mathrm{KN})$; $f_{y 0}$ - initial strength of the steel bars $\left(\mathrm{N} / \mathrm{mm}^{2}\right) ; f_{y}^{\prime}$ —strength damage threshold of steel bars $\left(\mathrm{N} / \mathrm{mm}^{2}\right) ; S_{0}$-initial sectional area of steel 
bars $\left(\mathrm{mm}^{2}\right) ; S_{1}$-sectional area after failure $\left(\mathrm{mm}^{2}\right)$. Select the strength standard value of the steel bar as its initial strength that is

$$
f_{y 0}=f_{y, k}
$$

The safety factor is 1.2 , so that the strength damage threshold of the steel bar is:

$$
f_{\mathrm{y}}^{\prime}=f_{y s} / 1.2
$$

When other factors are not considered, the sectional area of steel bars has not changed, $S_{0}=S_{1}$. Substituting formula (17) and formula (18) into formula (16), the threshold value of bearing capacity loss rate is calculated to be $16.67 \%$.

In the case of corrosion, not only the sectional area of steel will decrease, but also the yield strength will decrease. When the corrosion rate of steel bar is greater than $10 \%$ and less than $60 \%$, the yield strength before and after corrosion has the following relations:

$$
f_{\mathrm{ys}}=\frac{0.985-1.028 \rho_{\mathrm{s}}}{1-\rho_{\mathrm{s}}} f_{\mathrm{y}, \mathrm{k}}
$$

In the formula, $f_{y}$-yield strength of corroded steel bars: $f_{y, k}$-yield strength of steel bar before corrosion: $\varrho_{s}-$ cross sectional loss rate of steel bar.

Substituting formula (19) into formula (16), the following formula can be obtained.

$$
\frac{\Delta P}{P}=\frac{f_{\mathrm{y}, \mathrm{k}} S_{0}-f_{\mathrm{ys}} S_{1}}{f_{\mathrm{y}, \mathrm{k}} S_{0}}=0.015+1.028 \rho_{\mathrm{s}}
$$

When the loss rate threshold value of bearing capacity is $16.67 \%$, the corresponding steel section loss rate is obtained by formula (20), and it is $14.76 \%$. Because the test steel is completely immersed in water, it is considered that the corrosion of steel bar is overall and uniform, and the weight loss rate is linear with the cross-section loss rate of steel bar. Thus, the weight loss rate of the steel bar is $14.76 \%$, which is used as the threshold value of the grey prediction data sequence.

\section{Feasibility test of the grey prediction}

According to the characteristics of MATLAB, two file functions are compiled, namely GREYCCH and GREYNUM, and their basic algorithms are the same. GREYCCH is used to judge the feasibility of modeling, and GREYNUM is used to sequence grey prediction. The data sequence for the GM $(1,1)$ model under different corrosion conditions is shown in Tab. 2.

When the absolute value of the development coefficient is less than or equal to 0.3 , it is feasible to predict the weight loss rate of anchor specimens in the medium and long term by GM $(1,1)$ model. In order to further verify the feasibility of grey prediction by using the corrosion test data of steel bars, the first part of the original data sequence is used as the modeling data, and the rest of the experimental data is used as prediction and verification. The results are shown in Tab. 3 , the first 8 sets of data were used to predict the latter 3 sets of data, the predicted value and the actual value are relatively close, and the error is small. It shows that the grey prediction method is feasible and has high confidence.

\section{Results and analysis of grey prediction}

With the weight loss rate as the prediction sequence, the parameters, test indexes and prediction results of the model are shown in Tab. 4.

(1) From the parameters of $G M(1,1)$ model, it can be seen that the absolute values of the development coefficient are much less than 0.3, which shows that the model can be used for medium and long-term prediction. At the same time, the average precision of the model is more than 0.95 , and the maximum deviation of the average class ratio is only 0.0373 , which meets the requirements of modeling and the accuracy of the model is higher.

(2) From the comparison between the prediction curve and the original data points (as shown in Fig. 2-5), it can be seen that the prediction curve passes through the original data points and then develops upwards, and the development trend 
of the prediction curve and the original data points are consistent. In different working conditions, the development trend of curves is obviously different, but they are not linear, which is closer to the actual situation.

\begin{tabular}{cccccc}
\hline \multicolumn{2}{c}{ Data sequence } & Weight loss rate $/ \%$ & \\
$\begin{array}{c}\text { Serial } \\
\text { number }\end{array}$ & Time/month & $\begin{array}{c}\text { Close and } \\
\text { damp }\end{array}$ & $\begin{array}{c}\text { Permanently } \\
\text { soaked in water } \\
\text { alternately }\end{array}$ & $\begin{array}{c}\text { Weak acidity } \\
\text { aqueous soaking }\end{array}$ \\
2 & 1 & 0.0439 & 0.6609 & 0.4244 & 1.1408 \\
3 & 1.5 & 0.0608 & 0.6614 & 0.4973 & 1.4662 \\
4 & 2 & 0.0743 & 0.6622 & 0.5630 & 1.7147 \\
5 & 2.5 & 0.0851 & 0.6636 & 0.6214 & 1.9046 \\
6 & 3 & 0.0938 & 0.6659 & 0.6724 & 2.0496 \\
7 & 3.5 & 0.1007 & 0.6696 & 0.7161 & 2.1604 \\
8 & 4 & 0.1063 & 0.6758 & 0.7526 & 2.2450 \\
9 & 4.5 & 0.1108 & 0.6859 & 0.7817 & 2.3096 \\
10 & 5 & 0.1144 & 0.7027 & 0.8036 & 2.3590 \\
11 & 5.5 & 0.1173 & 0.7303 & 0.8181 & 2.3967 \\
\hline
\end{tabular}

Table 2: Data sequences modeled by GM $(1,1)$.

\begin{tabular}{|c|c|c|c|c|c|c|c|c|c|}
\hline \multirow[b]{2}{*}{$\begin{array}{l}\text { Corrosion envi- } \\
\text { ronment }\end{array}$} & \multicolumn{3}{|c|}{ Test 1} & \multicolumn{3}{|c|}{ Test 2} & \multicolumn{3}{|c|}{ Test 3} \\
\hline & $\begin{array}{l}\text { predicted } \\
\text { value } / \%\end{array}$ & $\begin{array}{c}\text { actual } \\
\text { value } / \%\end{array}$ & $\begin{array}{l}\text { error } \\
/ \%\end{array}$ & $\begin{array}{l}\text { predicted } \\
\text { value } / \%\end{array}$ & $\begin{array}{l}\text { actual val- } \\
\text { ue } / \%\end{array}$ & $\begin{array}{l}\text { error } \\
/ \%\end{array}$ & $\begin{array}{l}\text { predicted } \\
\text { value } / \%\end{array}$ & $\begin{array}{l}\text { actual val- } \\
\text { ue } / \%\end{array}$ & $\begin{array}{c}\text { error } \\
1 \%\end{array}$ \\
\hline Close and damp & 0.1241 & 0.1144 & -8.48 & 0.1333 & 0.117 & -13.64 & 0.1428 & 0.120 & -19.40 \\
\hline $\begin{array}{l}\text { Permanently } \\
\text { soaked in water }\end{array}$ & 0.6846 & 0.7027 & 2.32 & 0.6886 & 0.730 & 5.71 & 0.6925 & 0.776 & 10.74 \\
\hline $\begin{array}{l}\text { Wet and dry al- } \\
\text { ternately }\end{array}$ & 0.8592 & 0.8036 & -6.92 & 0.9224 & 0.818 & -12.75 & 0.9902 & 0.825 & -19.97 \\
\hline $\begin{array}{c}\text { Weak acidity } \\
\text { aqueous soaking }\end{array}$ & 2.5547 & 2.359 & -8.30 & 2.7192 & 2.397 & -13.46 & 2.8912 & 2.426 & -19.32 \\
\hline
\end{tabular}

Table 3: Feasibility verification of grey prediction.

\begin{tabular}{ccccccc}
\hline $\begin{array}{c}\text { Corrosion } \\
\text { environment }\end{array}$ & $\begin{array}{c}\text { Translation } \\
\text { value }\end{array}$ & $\begin{array}{c}\text { Development coef- Grey influencing coef- Mean accu- } \\
\text { ficient }\end{array}$ & $\begin{array}{c}\text { Mean stepwise ratio } \\
\text { ficients }\end{array}$ & $\begin{array}{c}\text { Predicted } \\
\text { deviation }\end{array}$ \\
Close and damp & 0.2 & -0.0207 & 0.2635 & 0.9840 & 0.0147 & 8.2 \\
$\begin{array}{c}\text { Permanently soaked in } \\
\text { water }\end{array}$ & 0 & -0.0159 & 0.6255 & 0.9796 & 0.0149 & 0.0373 \\
$\begin{array}{c}\text { Wet and dry alternately } \\
\begin{array}{c}\text { Weak acidity aqueous } \\
\text { soaking }\end{array}\end{array}$ & 0 & -0.0498 & 0.5234 & 0.9567 & 0.0068 & 3.2 \\
\hline
\end{tabular}

Table 4: Parameters and grey prediction results of GM $(1,1)$ model.

(3) From the predicted results, according to the selected weight loss rate threshold value, under the permanently soaked in water condition, the life of anchor steel bar is the longest, reaching 8.3 years; the life of anchor bar under close and damp condition is 8.2 years; the life of anchor bar under weak acidity aqueous soaking condition is the shortest, only 2.4 
years. This is because under the weak acid environment, the oxide film passivation layer formed on the steel bar surface is easily destroyed by acid water, which leads to faster corrosion and shorter service life of steel bars.

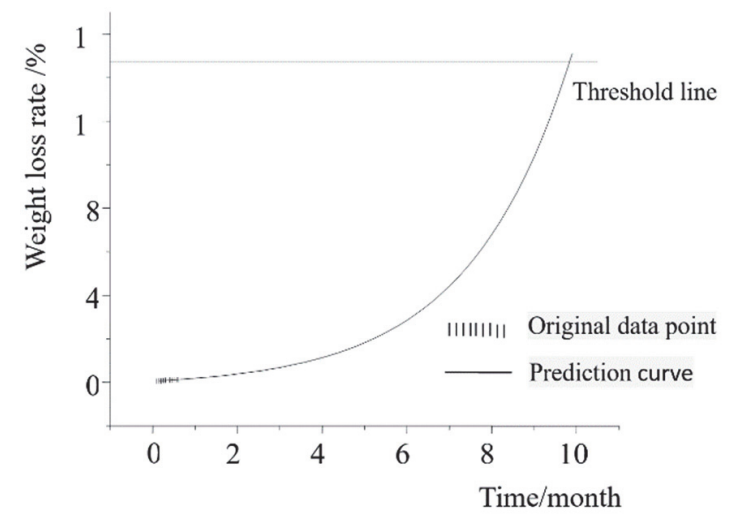

Figure 2: The Prediction curve and original data point at close and damp environment.

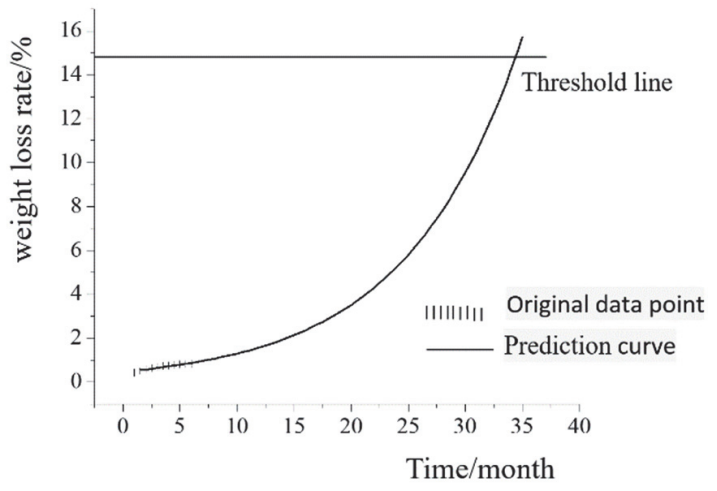

Figure 4. The Prediction curve and original data point at wet and dry alternately environment.

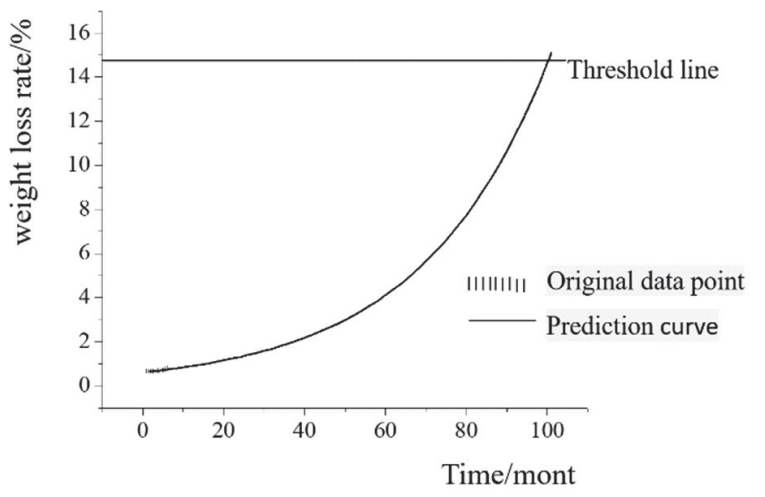

Figure 3. The Prediction curve and original data point at permanently soaked in water environment.

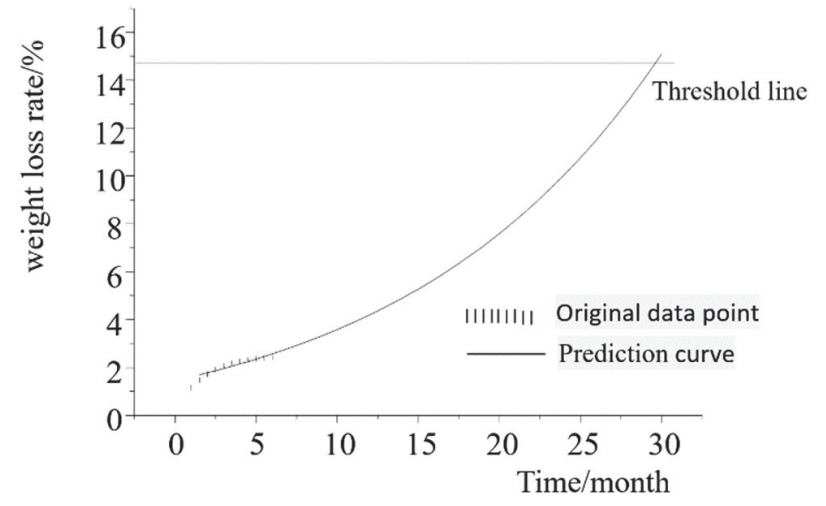

Figure 5. The Prediction curve and original data point at weak acidity aqueous soaking environment.

\section{CONCLUSION}

$\mathrm{B}$ ased on the combination of laboratory test and theoretical analysis, the durability and service life of the anchor structure are analyzed comprehensively by the grey system theory. The main conclusions are as follows:

(1) In four different corrosive environments (close and damp, permanently soaked in water, wet and dry alternately, weak acidity aqueous soaking), the weight loss rate of the anchor in weak acidity aqueous soaking environment is the biggest, and the weight loss rate of the anchor in close and damp environment is the smallest. In any environment, the weight loss rate of anchor increases with time, but the increase rate decreases with time.

(2) The GM $(1,1)$ model is used to test the data of another part by using some experimental data. The results are relatively close. It shows that it is feasible to predict the service life of anchor structures by using the $G M(1,1)$ model.

(3) Based on the existing test data, the grey prediction of the anchor service life under four conditions after the test period is carried out. The service life prediction results of the anchor under four conditions have high confidence.

\section{ACKNOWLEDGMENTS}

7 he authors are grateful to the anonymous referees for their valuable remarks and helpful suggestions, which have significantly improved the paper. This research is supported by the science and technology project of Henan province (Grant No: 172102310748); the young backbone teacher support program of Henan province colleges and universities (Grant No: 2015GGJS-120); the key research project of the Henan education department (Grant No: 
15B560008): and the natural science basic research projects of the Henan education department (Grant No. 2010B410004).

\section{REFERENCES}

[1] Wang, J.H., Yan, S., Zeng, X.M. and Li, S.M. (2006). Study and Application of Compound Soil Nail Support in China, Construction Technology, 35(1), pp. 15-19.

[2] Liu, B. and Wang, H. (2012). Application of Gray System Theories in Forecasting Daily Output of Oil, Journal of Chengde Petroleum College, (2), pp. 9-12. DOI: 10.13377/j.cnki.jcpc.2012.02.026

[3] Wang, F.J., Li, T.Q. and Yu, C.Z. (2006). Grey Verhulst Predictive Model of Road Traffic Accidents, Journal of Traffic and Transportation Engineering, 6(1), pp. 122-126.

[4] Yang, M.G. and Yang, X.X. (2010). Prediction for Inbound Tourism Flow of Chongqing Based on Grey Prediction Model, Journal of Southwest China Normal University (Natural Science Edition), 35(3), pp. 259-263. DOI: 10.13718/j. cnki. xsxb. 2010.03.064

[5] Wang, L., Ding, W., Ma, Y.F. and Zhang, J.R. (2011). Probabilistic model of shear resistance degradation for corroded reinforced concrete beam, Journal of Changsha University of Science and Technology (Natural Scienc), 8(4), pp. 34 41.

[6] Xiao, C.Y., Du, Z.Y., Guo, C. and Xia, J.B. (2008). The Computational Analysis of Flexural Bearing Capacity of Corroded Reinforced Concrete Beams, Journal of Hubei University of Technology, 28(1), pp. 25-27.

[7] Zhang, Y.H., Meng, Q.F. and Li, Y.Q. (2002). The nonlinear analysis of concrete simple-supported beams strengthened by external prestressing, Building science research of Sichuan, (1), pp. 27-29, 34.

[8] Zeng, X.M., Chen, Z.Y., Wang, J.T. and Du, Y.H. (2004). Research on safety and durability of bolt and cablesupported structures, Chinese Journal of Rock Mechanics and Engineering, 23(13), pp. 2235-2242.

[9] [9] Hong, H.C. and Xu, W.Y. (2008). Research on service life of wholly bonded prestressed cable when corrosion expansion cracking, Rock and Soil Mechanics, 29(4), pp. 949-953. DOI: 10.16285/j.rsm.2008.04.032

[10] Zhao, J., Ji, W.Z., Xiao, L., Liang, S.F., Yan, S., Wang, J.H. and Zeng, X.M. (2006). In-situ experimental study on anchor durability, Chinese Journal of Rock Mechanics and Engineering, 25(7), pp. 1377-1385.

[11] Prosek, T., Le Bozec, N. and Thierry, D. (2014). Application of automated corrosion sensors for monitoring the rate of corrosion during accelerated corrosion tests, Materials and Corrosion, 65(5), pp. 448-456.

[12] Montoya, P., Diaz, I., Granizo, N., Fuente, D.D.L. and Morcillo, M. (2013). A study on accelerated corrosion testing of weathering steel, Materials Chemistry and Physics, 142(1), pp. 220-228.

[13] Pacheco, A.R. and Schokker, A.J. (2007). Revisions to accelerated corrosion test method for post tensioning grout, ACI materials journal, 104(2), pp. 123-128.

[14] Rahman, M.S., Divi, S., Chandra, D. and Daemen, J. (2008). Effect of different salts on the corrosion properties of friction type A607 steel rock bolt in simulated concentrated water, Tunnelling and Underground Space Technology, 23(6), pp. 665-673.

[15] Darmawan, M.S. and Stewart, M.G. (2007). Spatial time dependent reliability analysis of corroding pretensioned prestressed concrete bridge girders, Structural Safety, 29(1), pp. 16-31.

[16] Divi, S., Chandra, D. and Daemen, J. (2011). Corrosion susceptibility of potential rock bolts in aerated multiionic simulated concentrated water, Tunnelling and underground space Technology, 26(1), pp. 124-129.

[17] Kim, J. and West, R.C. (2010). Application of the Viscoelastic Continuum Damage Model to the Indirect Tension Test at a Single Temperature, Journal of Engineering Mechanics, 136(4), pp. 496-505.

[18] Lopez, C.M., Carol, I. and Aguado, A. (2008). Meso-structural study of concrete fracture using interface Structure elements. II: compression, biaxial and Brazilian test, Materials and Structures, 41(3), pp. 601-620.

[19] Mashayekhi, M., Ziaei Rad, S., Parvizian, J., Niklewicz, J. and Hadavinia, H. (2007). Ductile crack growth based on damage criterion: Experimental and numerical studies, Mechanics of Materials, 39(7), pp. 623-636.

[20] Zhang, J. and Lounis, Z. (2009). Nonlinear relationships between parameters of simplified diffusion based model for service life design of concrete structures exposed to chlorides, Cement \&Concrete Composites, 31(8), pp. 591-600. 